The final publication is available at:

http://link.springer.com/article/10.1007\%2Fs11229-012-0179-7

\title{
What is interdisciplinary communication? Reflections on the very idea of disciplinary integration
}

\section{J. Britt Holbook}

Center for the Study of Interdisciplinarity, University of North Texas, 1155 Union Circle \#310920, Denton, TX 76203-5017, USA

e-mail: britt.holbrook@unt.edu

\begin{abstract}
In this paper I attempt to answer the question: What is interdisciplinary communication? I attempt to answer this question, rather than what some might consider the ontologically prior question-what is interdisciplinarity (ID)?-for two reasons: (1) there is no generally agreed-upon definition of ID; and (2) one's views regarding interdisciplinary communication have a normative relationship with one's other views of ID, including one's views of its very essence. I support these claims with reference to the growing literature on ID, which has a marked tendency to favor the idea that interdisciplinary communication entails some kind of 'integration'. The literature on ID does not yet include very many philosophers, but we have something valuable to offer in addressing the question of interdisciplinary communication. Playing some- what fast-and-loose with traditional categories of the subdisciplines of philosophy, I group some philosophers-mostly from the philosophy of science, social-political philosophy, and moral theory-and some non-philosophers together to provide three different, but related, answers to the question of interdisciplinary communication. The groups are as follows: (1) Habermas-Klein, (2) KuhnMacIntyre, and (3) Bataille- Lyotard. These groups can also be thought of in terms of the types of answers they give to the question of interdisciplinary communication, especially in terms of the following key words (where the numbers correspond to the groups from the previous sentence): (1) consensus, (2) incommensurability, and (3) invention.
\end{abstract}

Keywords Interdisciplinarity · Transdisciplinarity · Communication · Integration • Consensus · Incommensurability · Invention 
Disciplinarity should be treated as a necessary evil of knowledge production-the more necessary it is made to appear, the more evil it becomes.

\section{Introduction}

As Klein (2010) illustrates, scholars of interdisciplinarity (ID) today are quick to allow that there currently exists no generally agreed-upon definition of the term. Instead, there is a plethora of definitions, which are often accompanied by variations on the term [multidisciplinarity (MD), transdisciplinarity (TD), narrow, wide, and critical ID, and so forth]. Sometimes, these variations on 'ID' are meant to aid in defining what ID actually is. At other times, these variations are put forth to suggest that there simply is no one thing that counts as 'ID'. That it is so easy to generate new terms for supposedly new types of ID (for instance, the variations described in the last sentence might well be described as 'anti-essentialist ID', which is a new term) is no hindrance to having a discussion of ID, however-quite the contrary. Indeed, that the term 'interdisciplinarity' can be put to so many uses is part of its charm.

ID is, in fact, a hot topic of discussion among academics, as this special issue illustrates. In this paper, I will approach the notion of ID by way of a discussion of interdisciplinary communication. Socrates (were he to pop his head up out of the ground) might object that one cannot have a meaningful discussion about interdisciplinary communication before one establishes what ID itself is. I want to suggest, however, that in practice, one's view of interdisciplinary communication is normative of-perhaps even largely determines-what one thinks ID itself actually is. So, even if we cede a certain ontological priority to the question of the essence of ID, if we hope to arrive at such a definition, we would do well to begin our discussion with the question of communication.

\section{A baseline vocabulary}

Even if there is currently no single, agreed-upon definition of ID, there is, at least, something like a baseline common vocabulary for discussing ID and its cognates (MD, TD, and sometimes pluridisciplinarity). Klein $(1990,1996)$ traces the originary-if not the first-use of these terms to a 1970 conference held by the Organization for Eco- nomic Cooperation and Development (OECD). ${ }^{1}$ There has been some drift away from the original OECD usage-for instance, 'pluridisciplinarity' has essentially dropped out of the literature and TD has taken on an interesting new meaning in the last decade or so, thanks to both theoretical and practical developments in Europe, especially. But what we have now in the scholarly literature on ID is something approaching agreement on the use of the following terms:

- MD refers to the (mere) juxtaposition of two or more academic disciplines focused on a single problem.

1 Results of this conference were published in Apostel et al. (1972). 
- ID refers to the integration of two or more disciplines focused on a common (and, it is sometimes insisted, a complex) problem.

- TD refers to the integration of one or more academic disciplines with extraaca-demic perspectives on a common (and usually a real-world, as opposed to a merely academic) problem.

Beyond this basic vocabulary, however, there remains a great deal of conceptual space for making fine distinctions that, while aiming to expand our vocabulary, in fact lead to something more like a problem of taxonomy (Klein 2010). In what follows, I try to resist the urge to multiply terms. Instead, I attempt to explore the three main terms (MD, ID, and TD-though with a focus on ID) in the current literature in relation to the idea of communication. ${ }^{2}$

\section{On the very idea of integration}

If we examine our baseline vocabulary, the leading candidate for the distinguishing characteristic of ID is the notion of integration. What distinguishes ID from MD is the contrast between the mere juxtaposition of multiple academic disciplines in MD and the integration of those disciplines in ID. A multidisciplinary approach to a problem would involve multiple disciplines each investigating the problem in its own way, with its own definition of the problem, according to its own standards, and arriving at its own independent solution. MD involves no attempt to integrate these multiple disciplin- ary approaches. ID, on the other hand, at least according to our baseline vocabulary, just is the attempt to integrate multiple disciplinary approaches to a problem. What distinguishes TD from ID, on the other hand, is not the idea of integration per se, but rather what ought to be integrated. In the case of ID, what ought to be integrated are various academic disciplinary approaches to a problem; in the case of TD, what ought to be integrated are academic and non-academic stakeholders' approaches to a prob- lem. According to our baseline vocabulary, then, something can be interdisciplinary or transdisciplinary, or both-but it cannot be either unless it involves integration. Both ID and TD, thus, are distinguished from MD by means of the contrast between a mere juxtaposition of approaches and an integration of approaches.

\subsection{Integration entails communication beyond one discipline}

Insofar as no integration of various disciplinary approaches is necessary for MD, a multidisciplinary approach involves communication only within a particular discipline's

\footnotetext{
2 There currently exists no discipline of ID, though there are certainly candidates (the most explicit of which is Integration and Implementation Sciences under the direction of Gabriele Bammer). In what sense, then, is it possible to refer to a 'liter ature' on ID? Having surveyed the publications orga nized around trying, in part at least, to summarize the field (for instance, Hirsch Hadorn et al. 2008; Frodeman et al. 2010) and looked across organizations that address ID (for instance, COSEPUP, td-net, the Association for Integrative Studies, the Science of Team Science Conference, the Center for the Study of ID, and the International Network for ID and TD), I have found one figure associated with all: Julie Thompson Klein. In addition, with dozens of books and articles on the subject of ID, Klein is, in my judgment, the best place to begin drawing the boundaries of the current literature on ID.
} 
conceptual scheme. ID and TD, in contrast, involve extradisciplinary communication across the various conceptual schemes of different disciplines or non-academic stakeholder groups, respectively. That such extradisciplinary communication is necessary for ID and TD is entailed by the idea of integration. But exactly what sort of communication does the idea of integration presuppose?

\subsection{Communication requires translatability?}

At this point, it is difficult for a philosopher not to think of Donald Davidson's classic essay "On the Very Idea of a Conceptual Scheme" (1974). If we were to translate Davidson's discussion of conceptual schemes to our own discussion of interdisciplinary communication, we could say that disciplines each have-or perhaps are-some- thing like their own language, but these languages ought to be translatable. This is so because, as Davidson believes he has shown, the idea expressed in Sect. 3.1, that different disciplines are in fact different conceptual schemes, different ways of organizing or being tested by the facts of the world, is unintelligible. To paraphrase Davidson, adherents of different disciplines are merely words, not worlds, apart. The same can be said of academics who inhabit the Ivory Tower and the denizens of the "real world" - it is only a kind of linguistic confusion that leads us to accept scheme-content dualism, what Davidson calls the "third dogma" of empiricism.

\section{Varieties of interdisciplinary communication}

Davidson's attempt to expose the third dogma of empiricism ought to win him some readers within the field of scholarship on ID and TD. This is so because there is currently one dominant way of discussing interdisciplinary communication in the ID literature, and this dominant way of discussing interdisciplinary communication depends on a theory of meaning and understanding that seems highly compatible with Davidson's own opinions (cf. Schatzki 1986). I call this dominant view of interdisci- plinary communication the Habermas-Klein thesis, after the philosopher and critical theorist Jürgen Habermas and the ID scholar Julie Thompson Klein. Although I expect that readers of this journal are familiar with Habermas, I suspect that most are a great deal less familiar with the work of Klein, who is unquestionably among the world's leading scholars of ID. Briefly, the Habermas-Klein thesis holds that interdisciplinary communication involves the integration of two or more disciplinary languages with the aim of generating a common understanding. The Habermas-Klein thesis is in fact so dominant within scholarship of ID and TD there currently exists no fullfledged rival.

My intention in Sect. 4 of the paper, after briefly describing the dominant view of interdisciplinary communication, is to lay out two potential rival views: what I call the Kuhn-MacIntyre thesis and the Bataille-Lyotard thesis. The Kuhn-MacIntyre thesis, named after Thomas Kuhn and the philos opher and moral theorist Alasdair MacIntyre, calls into question the very idea of translation, and so it is in direct opposition to the Habermas-Klein thesis. The Kuhn-MacIntyre thesis holds that different disciplines are in fact incommensurable, and so interdisciplinary communication can only happen 
if one learns the language of another discipline from within as a second-first language. I call the second rival view of interdisciplinary communication the Bataille-Lyotard thesis, after the French thinker Georges Bataille and philosopher Jean-François Lyotard. According to the Bataille-Lyotard thesis, incommensurability only reveals itself when attempts at communication fail (they often succeed), at which point we can see that interdisciplinary communication is possible only through a process of inventing a new language. It is, of course, also the case that these two rival views are related to the positions of full and partial untranslatability that Davidson believes he has shown to be unintelligible.

I lay out each of the rival views of interdisciplinary communication in more detail in Sects. 4.1-4.3. Before doing so, however, I want to emphasize that rather than assert- ing an actual connection between the thought of these thinkers and scholarship of ID and TD, I am appealing to a family resemblance between elements of their thought and potential different ways of thinking about interdisciplinary communication. To be even more clear: except for Klein, none of the thinkers after which the three theses concerning interdisciplinary communication are named ought to be called a scholar of ID and TD. Moreover, I have no intention here of engaging in detailed scholarship on the work of Habermas, Kuhn, MacIntyre, Bataille, or Lyotard. My aims are to provide alternatives to the idea of integration and to open the door for philosophers to discuss the theory of ID in connection with the existing ID literature.

\subsection{The Habermas-Klein thesis}

The Habermas-Klein thesis holds that ID communication involves the integration of two or more disciplinary languages with the aim of generating a common under- standing. Klein herself often refers to Habermas in discussing ID communication [see especially Klein (2005) and (2011) and Klein and Pohl (under review)]; and when she does so, she also often links her discussion of interdisciplinary communication with the notion of integration. Indeed, Klein (2005) goes so far in linking interdis- ciplinary communication with the notion of integration that she considers what she calls "linguistic and communication models" and "stage and process models" to be two insightful ways of looking at the notion of integration. I will return to "stage and process models" of integration shortly; on "linguistic and communication models" of integration, she writes: "Interdisciplinarity entails communicative action" (Klein 2005, p. 42).

According to Habermas (1976, p. 22, emphasis in original) anyone involved in communicative action is committed to the following validity claims:

She claims to be
a. uttering something intelligibly,
b. giving (the hearer) something to understand,
c. making herself thereby understandable, and
d. coming to an understanding with another person.

One's commitment to understanding is necessary in order to "bring about an agreement that terminates in the intersubjective mutuality of reciprocal comprehension, shared knowledge, mutual trust, and accord with one another" (Habermas 1976, p. 23). If we 
return to the realm of ID, then, we can say that interdisciplinary communication aims at achieving this kind of reciprocal comprehension, shared knowledge, and, in short, consensus between actors from different disciplines.

Both Habermas and Klein insist that such common ground is far from the normal state of communication, which is almost always something messier, something to be found in the all too common gray areas between, for instance, miscommunication and lying; and this is why, quips Habermas, we speak of "bringing about an agree- ment" (1976, p. 23, emphasis in original). For her part, Klein (2005, p. 44) insists that "interdisciplinarity conceived as communicative action rejects the naïve faith that everything will work out if everyone just sits down and talks to each other." Interdisciplinary communication is rife with miscommunication: "the crux of the matter is difference," according to Klein (2005, p. 43). But it is precisely for this reason that both Klein and Habermas seek consensus. For instance, after discussing the problems arising from the fact that there are over 100 definitions of the term 'desertification', Klein concludes: "Any interdisciplinary effort, then, requires analyzing terminology to improve understanding of phenomena and to construct an integrated framework with a common vocabulary" (2005, pp. 43-44).

The general consensus on seeking consensus in the ID literature has led some theorists of ID to propose what Klein terms "stage and process models" of integration. Klein herself proposes such a model, but she subordinates it to the notion that ID is communicative action. For Klein, then, even if consensus is the ideal, difference is the norm. Others, however, have gone so far as to propose a particular method for reaching consensus. ${ }^{3}$ A recent instantiation of this approach can be found in Repko et al. (2011, p. xx):

- State the problem or focus question (Step 1)

- Justify using an interdisciplinary approach (Step 2)

- Identify relevant disciplines (Step 3)

- Conduct the literature search (Step 4)

- Develop adequacy in each relevant discipline (Step 5)

- Analyze the problem and evaluate each insight into it (Step 6)

- Identify conflicts between insights and their sources (Step 7)

- Create or discover common ground (Step 8)

- Integrate insights (Step 9)

- Produce an interdisciplinary understanding and test it (Step 10)

Readers who react to such apparent linearity with dubiousness are "encouraged to consult Repko (2008) for a detailed discussion of the steps in the research process and the recommended guidelines or strategies for performing each of them" (Repko et al. 2011, p. xx).

Klein has attempted to appeal to the notion of ID as communicative action in order to resist the reduction of ID to a method. Like Habermas, Klein insists that the aim of consensus serves as an ideal with which to critique attempts to 'bring about' an agreement. However, as illustrated by "stage and process models" of integration, talk

\footnotetext{
3 For a discussion of this trend, as well as an overarching reflection on ID, see Robert Frodeman (2010) introduction to The Oxford Handbook of Interdisciplinarity.
} 
of consensus and 'bringing about agreement' can easily slip into a method that need only be followed in order to achieve common ground.

In a further effort to combat the methodical integrationists, Klein raises the possibilities of pidgins, trading zones, and creoles (Galison 1997). Her point is to emphasize that difference, rather than similarity, can lead to fruitful exchange-a point that Galison makes repeatedly. However, insofar as she still relies on the language of integration and the ideal of consensus, Klein's efforts to emphasize difference have little impact on the methodical integrationists' conquest of common ground. ${ }^{4}$ The reason for the ongoing disagreement between both types of integrationist, I suggest, is not that the methodical and the communicational integrationists lack common ground that might allow them to reach consensus. Instead, the problem is that theorists of ID who want to emphasize differenceincluding Klein herself-currently have no language that does not also appeal to consensus in which to make their case. ${ }^{5}$ If interdisciplinary com- munication is only about reaching consensus, then ID itself can be nothing other than integration-that is, achieving sameness. ${ }^{6}$ In Sects. 4.2 and 4.3 , I attempt to provide two possible alternative accounts of interdisciplinary communication.

\subsection{The Kuhn-MacIntyre thesis}

According to the Kuhn-MacIntyre thesis, different disciplines are in principle and often in fact incommensurable, and so ID communication can only happen if one first learns the language of another discipline from within as a second-first language. On the Kuhn-MacIntyre view, it is simply not possible to judge one discipline according to the standards of another; or, at least, it is not rational to do so. It is possible, however, for the adherent of one discipline to adopt the viewpoint of another. According to the Kuhn-MacIntyre thesis, what happens when the adherent of one discipline adopts the viewpoint of another discipline ought not to be described as a translation, however. Moreover, adoption of a different disciplinary viewpoint is something that requires significant time and a significant commitment.

Kuhn, with his talk of scientists inhabiting "different worlds" and the notion of a paradigm, is one of Davidson's whipping boys: he suffers at Davidson's hands for the sins of all relativists, almost as much as Protagoras suffered at the hands of Plato. Davidson (1974) argues that the very idea of incommensurable conceptual schemes is unintelligible. Kuhn (2000) offers a succinct reply to Davidson's critique: translation and interpretation are very different activities. From Kuhn's point of view, Davidson's

\footnotetext{
4 For another example of Klein's unsuccessful attempts to distance herself from the methodical integra- tionists, see the exchange between Newell and Klein in Issues in Integrative Studies, 19, 2001.

5 Of course, as one reviewer pointed out, this does not mean that there exists no language for describing crossdisciplinary collaboration that does not aim at consensus. In addition to the notions of trading zones, pidgins, and creoles developed by Galison (1997), Star and Griesemer (1989) notion of boundary objects explicitly deals with collaborations that are not governed by an ideal of consensus. My point is that the language of integration and consensus is inadequate to deal with such notions. Trying to wedge them into the Habermas-Klein thesis is therefore akin to trying to fit the proverbial square pin into the round hole.

6 Indeed, the use of a boundary object to facilitate collaboration not aimed at consensus ought to count only as MD rather than ID under the Habermas-Klein thesis.
} 
conflation of these notions makes it possible to argue that translation from one language to another is the mark of understanding (I understand the German sentence 'Schnee ist weiss' when I recognize the truth of the proposition: 'Schnee ist weiss' is true if and only if snow is white). From this, Davidson concludes that incommensurability between different conceptual schemes, which he understands as untranslatability, is actually unintelligible. Kuhn's reply is that understanding requires something other than mere translation; understanding requires interpretation.

In Whose Justice? Which Rationality? Alasdair MacIntyre offers an excellent account of the relationship between translatability, incommensurability, and rational-ity-an account that further develops Kuhn's reply to Davidson. MacIntyre compares Davidson's notion of translation to the use of a phrasebook to get along in a foreign country in which a different language is spoken. According to MacIntyre, assenting to the claim that 'Snow is white' is insufficient to demonstrate an understanding of English, which is marked by being able to improvise and innovate: "It is this knowing how to go on and go further which is the badge of elementary linguistic competence" (1988, p. 382). A competent speaker of English would be able to generate the following sentence: "Snow is white and so are the members of the Ku Klux Klan, and white with fear is what they were in snowcovered Arkansas last Friday" (MacIntyre 1988, p. 382).

Achieving linguistic competence, then, is no matter of mere translation. Indeed, MacIntyre suggests that translation from the language that one is attempting to learn into the language one already speaks may interfere with the achievement of linguistic competence in the new language: "[New languages] have to be learned as second first languages or not at all" (1988, p. 375). Learning a new language as a second first language requires that one "become a child again" (MacIntyre 1988, p. 374). Having learned a second first language, one can not only go on and go further, but also one can find instances in which it is not possible to translate from one language to the other.

MacIntyre's account of learning a second first language is by no means limited to natural languages. In fact, his Three Rival Versions of Moral Enquiry (1990) is largely an attempt to learn the language of a rival version of moral enquiry (that instituted by Nietzsche) in order to show that MacIntyre's own Thomistic tradition of moral enquiry is rationally superior. He writes:

... These lectures have as one of their aims to show ... that an admission of sig- nificant incommensurability and untranslatability in the relations between two opposed systems of thought and practice can be a prologue not only to rational debate, but to that kind of debate from which one party can emerge as undoubt- edly rationally superior (see Whose Justice? Which Rationality? chapters XVII, XVIII, and XIX), if only because exposure to such debate may reveal that one of the contending standpoints fails in its own terms and by its own standards. (1990, p. 5).

From his perspective MacIntyre contends that an effective rational debate, effective precisely because resolvable, can take place between incommensurable systems of thought. Such a debate is resolvable, however, only on the condition that members of one system of thought resist the urge to translate claims made in the alien system of thought into their own language, but instead learn the language of the alien system as a 
second first language; such a 'linguist' would then be able to judge the rationality of the alien system from the perspective of that system itself (MacIntyre 1988, chapter XIX). That is, having learned the language of an alien system as a second first language, one may then point out rational deficiencies within that system, deficiencies that can be understood as deficiencies by members of that system just insofar as those deficiencies are described in their own terms. MacIntyre's strategy is to learn 'Nietzschean' as a second first language and to show that the Nietzschean system is, in its own terms and by its own standards, rationally deficient.

MacIntyre's account of the rational resolvability of a dispute between rival systems of thought differs from Kuhn's notion of a paradigm shift precisely in that, for Kuhn, the shift from one paradigm to another is not rational. Both Kuhn and MacIntyre, however, provide an alternative to the notion of integration and consensus provided by the Habermas-Klein thesis.

For both Kuhn and MacIntyre, it makes sense to think of different conceptual schemes, whether different paradigms for Kuhn or different traditions of moral enquiry for MacIntyre, the claims to truth of which are not translatable. This is so because Kuhn and MacIntyre share a rich notion of translatability that involves much more than Davidson allows. Kuhn in fact rejects Davidson's talk of translation, preferring instead to talk of interpretation. MacIntyre, on the other hand, opposes a weak notion of translatability to a strong notion of linguistic competence that comes from learning the language of a rival scheme as a second first language. Appreciation for incommen- surability is one of the marks of linguistic competence for MacIntyre.

\subsubsection{Interdisciplinary communication according to the Kuhn-MacIntyre thesis}

If we apply Kuhn's and MacIntyre's views to interdisciplinary communication, what emerges is a very strong requirement for ID that recognizes the reality of incommensu- rability. Essentially, one would have to adopt the point of view of a different discipline in order for interdisciplinary communication to take place. One can imagine various options for accomplishing the adoption of a new disciplinary perspective. The most obvious option, perhaps, would be to earn proficiency in another discipline, say by pursuing a second $\mathrm{PhD}$. Another option would be to try to achieve what Collins and Evans (2002) have called 'interactional expertise' where one learns to 'talk the talk' of another discipline even if one cannot quite 'walk the walk'. ${ }^{7}$

Interdisciplinary communication according to the Kuhn-MacIntyre thesis would not aim at a consensus between adherents of the different disciplines. Instead, the need for interdisciplinary communication would arise when members of one disci- pline realize that they do not possess the ability to address a problem in a satisfactory way using only the resources native to that discipline. In order to solve such a problem, members of a discipline may reach out to members of another discipline to try to find the resources currently lacking in their own discipline.

\footnotetext{
7 See also Whyte and Crease (2010) for an interesting discussion of interactional expertise and trust.
} 


\subsubsection{MD, ID, and TD according to the Kuhn-MacIntyre thesis}

MD would occur when there is collaboration without sufficient sharing of expertise to rise to the level of ID. MD would shift into ID once there has been enough interaction that the members of one discipline can 'talk the talk' of the other discipline-that is, once they have reached a level of linguistic competence that they are conversation- ally indistinguishable from members of the other discipline (Collins and Evans 2002). One could distinguish ID from TD in much the same way that the current baseline vocabulary does so: TD differs from ID not in terms of the how of communication (it is still about learning to talk the talk of the other), but rather in terms of the what the communication is between (members of different academic disciplines in the case of ID, members of an academic discipline with non-academic scheme-inhabitants in the case of TD). On such a view, neither ID nor TD would be seen as integration. Indeed, with its strong focus on incommensurability, the Kuhn-MacIntyre thesis is diametrically opposed to the idea of ID as integration. There is, however, a strong focus on interaction between the disciplines.

\subsection{The Bataille-Lyotard thesis}

The Bataille-Lyotard thesis holds that incommensurability only reveals itself when attempts at communication fail (they often succeed), at which point further commu- nication is possible only through a process of inventing a new language. In his essay on Genet from Literature and Evil Georges Bataille (1993) opposes what he calls a strong, powerful sense of communication to a weak, feeble sense of communication. According to Bataille, it is precisely in opposition to weak communication that pow- erful communication most clearly manifests itself: "Communication, in my sense of the word, is never stronger than when communication, in the weak sense, the sense of profane language or, as Sartre says, of prose which makes us and the others appear penetrable, fails and becomes the equivalent of darkness" (p. 199). Weak communication takes place through what Bataille calls the profane use of language, a use that produces the appearance of clarity: “... the profane is the world of reason, of identity, of things, of duration and calculation. Each thing, in this world, receives a meaning in a durable relation with an other: such is the intelligible world, where perceptible elements are reduced to operating signs and have value only in view of ulterior possibilities" (1988, p. 40Bataille's italics).

As we operate in the profane world, we use weak communication "in order to convince people to agree with us. We want to establish humble truths which coordinate our attitudes and activity with those of our fellow human beings" (Bataille 1993, p. 199). Bataille's weak communication is thus used for the purposes of gaining a clear understanding of the things that constitute the objective world and of establishing a consensus as to how we ought to act in order to be productive members of society. It is precisely to the extent that we understand one another with a view to productive activity that we and others "appear penetrable" to each other.

Strong communication, on the other hand, manifests itself at moments when weak communication breaks down. As long as we remain active and productive, as longas 
we understand each other, we appear penetrable to one another. A failure of under- standing, however, gives rise to a moment "when subjectivity seems unintelligible in relation to the intelligibility of customary objects and, more generally, of the objective world" (Bataille 1993, p. 200). Strong communication, then, is an experience of not being able to find the words-an experience that Jean-François Lyotard terms a 'differend'.

According to Lyotard, a differend occurs when the rules of one genre of discourse are used to settle a dispute between parties from different genres of discourse.

As distinguished from a litigation, a differend would be a case of conflict, between (at least) two parties, that cannot be equitably resolved for lack of a rule of judgment applicable to both arguments. One side's legitimacy does not imply the other's lack of legitimacy. However, applying a single rule of judgment to both in order to settle their differend as though it were merely a litigation would wrong (at least) one of them (and both if neither side admits this rule). Damages result from an injury which is inflicted upon the rules of a genre of discourse but which is reparable according to those rules. A wrong results from the fact that the rules of the genre of discourse by which one judges are not those of the judged genre or genres of discourse. (1988, p. xi)

A litigation settles disputes between parties who agree on the same rule of judgment, i.e., parties from within the same genre of discourse. A differend, on the other hand, takes place between those associated with different genres of discourse. For Lyotard, genres of discourse determine stakes, the goal toward which phrases move:

The stakes of a genre are often set by a phrase of canonical value.... Success comes from giving an "answer" to the key-phrase. The "answer" is a phrase that suspends the question contained in the keyphrase. It is then asked whether this suspension is legitimate, and the answer to this last question becomes the object of new differends, whose various parties question the said answer on the basis of key questions which set the stakes for their respective genres. (1988, p. 137)

Let us suppose that we ask the question: what is the best way to set up a legal sys- tem? We could answer that, for instance, (a) one ought always to presume innocence and have to prove guilt; alternatively, one might answer that (b) one ought always to presume guilt and have to prove innocence. Proponents of answer (a) might then question whether proponents of (b) think it is better wrongly to convict innocents or wrongly to free those who are guilty. The conversation could continue until one had two well-developed, yet incommensurable, genres of legal discourse between which a differend would be possible.

\subsubsection{Interdisciplinary communication according to the Bataille-Lyotard thesis}

If we take genres of discourse as the rough equivalent of disciplinary languages, then according to the Bataille-Lyotard thesis, the sort of communication that takes place within a particular discipline is usually of the weak variety. Disagreements obviously happen among the adherents of a single discipline. But disputes that we can settle among ourselves according to our normal disciplinary standards would count as 
litigations, not differends. The same can also apply to communication between adherents of different disciplines. It is often possible to settle interdisciplinary disagreements on disciplinary terms, that is, on terms acceptable to the adherents of each discipline. It is even possible to avoid many interdisciplinary disagreements, for instance, by utilizing boundary objects to orient the discussion (Star and Griesemer 1989).

On the other hand, it may sometimes happen that we are not able to find the words to settle our dispute. Although such a breakdown of communication is possible within disciplines, it is much more likely to happen between different disciplines. A differend, marked by the feeling of not being able to find the words, of the breakdown of normal, weak communication, is the first moment of strong interdisciplinary communication under the Bataille-Lyotard thesis. The second moment of strong interdisciplinary communication under the Bataille-Lyotard thesis is the invention of a new genre of discourse, one that is not merely an integration of the previously existing genres, but a novel co-creation of those who have risked and relinquished their previous disciplinary identities.

\subsubsection{MD, ID, and TD according to the Bataille-Lyotard thesis}

According to the Bataille-Lyotard thesis, the assumption that disciplines are the best reference point when describing scholarly communication is called into question. Indeed, the distinctions between MD, ID, and TD under the baseline vocabulary can be jettisoned. The important question is not whether different disciplines are integrated with each other (as in the base vocabulary's understanding of ID), integrated with non- academic understandings (as in the baseline vocabulary's understanding of TD), or merely juxtaposed (as in the base vocabulary's understanding of MD). Instead, the question to ask is whether we can proceed as if we all understand one another (weak communication) or not (a differend).

Whenever weak communication is possible, whether it is between adherents of the same discipline, different disciplines, or disciplinary adherents with non-academics, there is no reason to distinguish between MD, ID, and TD. When we all understand each other, such distinctions do no real work. On the other hand, in situations in which weak communication breaks down, that is, whenever what is at stake for an adherent of a particular genre of discourse (whether disciplinary or non-academic) becomes open to question, that individual's identity is risked and the possibility of strong communication opens up-provided that the other's identity, what is at stake for the other, is also risked. The distinction between a disciplinary and a non-disciplinary genre of discourse-and the accompanying distinction between ID and TD-does very little work according to the Bataille-Lyotard thesis. The point is rather to let go of one's prior commitment to a particular genre of discourse (whether disciplinary or not) in order to allow for the possibility of strong communication and the invention of a new genre of discourse. This mutual willingness to risk our identities may eventually be manifested in the creation of a new genre of discourse. 8

\footnotetext{
8 The creation of a new genre of discourse may be fruitfully compared with what Galison (1997) has termed the generation of a creole in his discussion of trading zones. Where Galison speaks of developing local agr eement despite global differences, the creation of a new genre happens when participants give up
} 


\section{Summary}

The notion of 'integration' is so widespread in the ID literature that to question whether ID involves integration is almost heretical. ${ }^{9}$ I have argued (in Sect. 4), however, that there are two rival notions of interdisciplinary communication that ought to be con- sidered: in addition to the Habermas-Klein thesis (ID $\rightarrow$ integrative consensus), we ought to consider the Kuhn-MacIntyre thesis (ID $\rightarrow$ recognizing incommensurabil- ity) and the Bataille-Lyotard thesis (ID $\rightarrow$ reflective invention). There are interesting practical consequences to this theoretical debate. The US National Academies issued a report on Facilitating Interdisciplinary Research (COSEPUP 2004) that incorporates an understanding of ID consistent with the Habermas-Klein thesis. Universities and funding agencies around the world are beginning to incorporate the recommendations contained in this report. But what if there are overlooked conceptual issues with the Habermas-Klein thesis? I believe there are some issues. I also think that, insofar as the Habermas-Klein thesis remains the dominant discourse of ID, these issues could lead to significant problems with the ways in which ID is institutionalized and evaluated.

One important issue with the current literature on ID is that the consensus surround- ing the notion of integration is chimerical. Some (for instance, Klein) see consensus as an ideal goal, a kind of regulator of the fundamental disagreement that underlies the discussion between different disciplines. Others (for instance, Repko, Newell, and Szostak) see consensus as something that can actually be achieved by following the correct method. A second problem with the current literature on ID is the very notion of integration itself. What is integration? Is it a noun (the state of having reached a consensus)? Or does its verbal character dominate (such that integration is the act of joining together)? A third, related issue has to do with what, exactly, is being integrated. What are disciplines, such that they can be merely juxtaposed (MD) or integrated (ID)? Are disciplines themselves integrations? Of what? And what, precisely are disciplines integrated with in the case of TD? In taking disciplines as givens, the Habermas-Klein thesis neglects an important factor in describing interdisciplinary communication.

What the Habermas-Klein thesis neglects is the possibility (some might say fact) of incommensurability between disciplines. According to the Kuhn-MacIntyre thesis, a discipline is a sort of conceptual scheme whose adherents share some basic orienta- tions toward the world. Because these basic orientations can differ in important ways, communication between disciplines (ID) can only happen when one learns another discipline from within, as a sort of second first language. This allows for the possibility of dialogue between disciplines, as long as the discussion is held on disciplinary terms. Something similar can happen with other, nonacademic conceptual schemes (TD).

\footnotetext{
Footnote 8 continued

their prior identities in order to forge a new genre. Whether that new genre is an area of global or local agreement is an interesting question. The creation of a new genre of discourse may also be compared with the idea of the cocreation of socially robust knowledge outlined under the rubric of Mode 2, especially in the sense that one's expertise, which for an academic is rooted in one's disciplinary identity, is risked (Gibbons et al. 1994).

9 Latucca (2001) provides an excellent critical account of the reduction of ID to in tegration (see especially pp. 10-14).
} 
What cannot happen according to the Kuhn-MacIntyre thesis, however, is integration, which will always result in what the adherents of a particular conceptual scheme would characterize as a misunderstanding.

According to the Bataille-Lyotard thesis, the key issue is not the difference between disciplines or conceptual schemes, but rather the possibility of communication between individuals who may be adherents of such genres of discourse. Insofar as communi- cation proceeds without major issues, we all understand each other, regardless of our disciplinary identities and languages. As long as such (weak) communication is pos- sible, whether we are from the same or different disciplines or from no discipline at all is of no import. It is when such communication breaks down, however, that the question of our disciplinary identities arises. To which genre of discourse do we belong? We can certainly answer by reasserting our (disciplinary) identities. In doing so, however, we forego the possibility of strong (interdisciplinary) communication. Such communication is possible only between individuals who risk their disciplinary identities and sacrifice them to the possibility of co-creating a new, shared genre of discourse.

A political scientist writing about philosophical work on the question of ID renders the following verdict (while referring to Klein 1990):

The philosophical perspective on disciplinarity and disciplinary discourses is only a side show in the overall ID debate, as the epistemological dimension and implications of disciplinarity or ID are rarely considered. (Krishnan 2009)

With this paper, I hope to have provided something of a reply to this charge. Indeed, with this special issue, one can hope that we philosophers are regaining interest in re-opening the question of ID. ${ }^{10}$

\section{References}

Apostel, L., Berger, G., Briggs, A., \& Michaud, G. (Eds.). (1972). Interdisciplinarity: Problems ofteaching and research in universities. Paris: Organization for Economic Co-operation and Development.

Bataille, G. (1988). Inner experience (L. A. Boldt, Trans.). Albany: SUNY Press.

Bataille, G. (1993). Literature and evil (A. Hamilton, Trans.). New York: Marion Boyers.

Collins, H. M., \& Evans, R. J. (2002). The third wave of science studies: Studies of expertise and experience. Social Studies of Sciences, 32(2), 235-296.

COSEPUP. (2004). Facilitating interdisciplinary research. Committee on Science, Engineering, and

Public Policy (COSEPUP). Washington, DC: National Academies Press.

Davidson, D. (1974). On the very idea of a conceptual scheme. In Proceedings and Addresses of the American Philosophical Association (vol. 47, pp. 5-20). Newark: American Philosophical Association.

Frodeman, R. (2010). Introduction. In R. Frodeman, J. T. Klein, \& C. Mitcham (Eds.), The Oxford handbook of interdisciplinarity (pp. xxix-xxxix). Oxford: Oxford University Press.

Frodeman, R., Klein, J. T., \& Mitcham, C. (Eds.). (2010). The Oxford handbook of interdisciplinarity. Oxford: Oxford University Press.

Galison, P. (1997). Image \& logic: A material culture of microphysics. Chicago: The University of Chicago Press.

10 Scholars who ought to be drawn in to this discussion include contributors to Gorman (2010), Plaisance and Fehr (2010), and Stone (2011), am ong others. 
Gibbons, M., Limoges, C., Nowotny, H., Schwartzman, S., Scott, P., \& Trow, M. (1994). The new production of knowledge: The dynamics of science and research in contemporary societies. London: Sage.

Gorman, M. (2010). Trading zones and interactional expertise: Creating new kinds of collaboration. Boston: MIT Press.

Habermas, J. (1998 [1976]). What is universal pragmatics? In M. Cooke (Ed.), On the pragmatics of communication (pp. 21-104). Boston: MIT Press.

Hirsch Hadorn, G., et al. (2008). Handbook of transdisciplinary research. Dordrecht: Springer. Klein, J. T. (1990). Interdisciplinarity: History, theory, and practice. Detroit, MI: Wayne State University

Press.

Klein, J. T. (1996). Crossing boundaries: Knowledge, disciplinarities, and interdisciplinarities in the series on knowledge: Disciplinarity and beyond. Charlottesville, VA: University Press of Virginia. Klein, J. T. (2005). Interdisciplinary teamwork: The dynamics of collaboration and integration. In S. J. Derry, C. D. Schunn, \& M. A. Gernsbacher (Eds.), Interdisciplinary collaboration: An emerging cognitive science (pp. 23-50). Mahwah, NJ: Lawrence Erlbaum.

Klein, J. T. (2010). A taxonomy of interdisciplinarity. In R. Frodeman, J. T. Klein, \& M. Mitcham (Eds.), The Oxford handbook of interdisciplinarity (pp. 15-30). Oxford: Oxford University Press.

Klein, J. T. (2011). Research integration: A comparative knowledge base. In A. F. Repko, W. H. Newell, \& R. Szostak (Eds.), Interdisciplinary research: Case studies of integrative understandings of complex problems (pp. 283-298). Thousand Oaks, CA: Sage.

Krishnan, A. (2009). What are academic disciplines? Some observations on the disciplinarity vs. interdisciplinarity debate. ESRC National Centre for Research Methods, NCRM Working Paper Series. http://eprints.ncrm.ac.uk/783/1/what_are_academic_disciplines.pdf. Accessed 1 May 2012.

Kuhn, T. S. (2000). The road since structure. Chicago: University of Chicago Press.

Latucca, L. R. (2001). Creating interdisciplinarity: Interdisciplinary research and teaching among college and university faculty. Nashville, TN: Vanderbilt University Press.

Lyotard, J.-F. (1988). The differend: Phrases in dispute. Minneapolis, MN: University of Minneso ta Press.

MacIntyre, A. (1988). Whose justice? Which rationality?. Notre Dame, IN: Notre Dame University Press.

MacIntyre, A. (1990). Three rival versions of moral enquiry. Notre Dame, IN: Notre Dame University Press.

Newell, W. H., \& Klein, J. T. (2001). Issues in integrative studies (vol. 19). http://www.units.muohio. edu/aisorg/pubs/issues/toc_vol19.shtml.

Plaisance, K. S., \& Fehr, C. (Eds.). (2010). Making philosophy of science more socially relevant. Synthese, 177(3), 301-492.

Repko, A. F. (2008). Interdisciplinary research: Process and theory. London: Sage Publications. Repko,

A. F., Newell, W. H., \& Szostak, R. (Eds.). (2011). Interdisciplinary research: Case studies of integrative understandings of complex problems. Thousand Oaks, CA: Sage.

Schatzki, T. (1986). The rationalization of meaning and understanding: Davidson and Habermas. Synthese, 69, 51-79.

Star, S. L., \& Griesemer, J. R. (1989). Institutional ecology, 'translations,' and boundary objects: Amateurs and professionals in Berkeley's Museum of Vertebrate Zoology, 1907-1939. Social Studies of Science, 19, 387-420.

Stone, D. (2011). The experience of the tacit in multi- and interdisciplinary collaboration. Phenomenology and the Cognitive Sciences. http://dx.doi.org/10.1007/s11097-011-9248-5. Accessed 1 May 2012.

Whyte, K. P., \& Crease, R. P. (2010). Trust, expertise, and the philosophy of science. Synthese, 177, 411425. 